\title{
Analysis of mono-, di-, triacylglycerols, and fatty acids in food emulsifiers by high-performance liquid chromatography-mass spectrometry
}

\author{
Dinah Schick $^{1} \cdot$ Katharina Link ${ }^{1} \cdot$ Wolfgang Schwack $^{1} \cdot$ Michael Granvogl $^{1} \cdot$ Claudia Oellig $^{1}$
}

Received: 14 October 2020 / Revised: 22 December 2020 / Accepted: 30 December 2020 / Published online: 19 February 2021

(c) The Author(s) 2021

\begin{abstract}
Mono- and diacylglycerols (MG/DG) of fatty acids (FA), known as emulsifiers of the type E 471, are food additives used to adjust techno-functional properties of various foodstuffs. These emulsifiers, however, are not defined single compounds but comprise, in addition to MG and DG, other constituents such as FA, triacylglycerols (TG), and glycerol. Although the emulsifiers' compositions affect techno-functional properties of the food, knowledge of the composition is scarcely available, and the emulsifiers and their dosage are generally chosen empirically. Thus, a simple and rather inexpensive method for the simultaneous determination of FA, 1-MG, 2-MG, 1,2-DG, 1,3-DG, and TG by high-performance liquid chromatographymass spectrometry including a straightforward quantitation strategy has been developed. Reversed-phase chromatography with gradient elution offered adequate separation of 29 considered analytes within 21 peaks, while mass-selective detection provided their unequivocal identification. The quantitation strategy based on calibration just with the C16:0 representatives of each lipid class and a corresponding response factor system has proven to provide reliable results. The determined concentrations of different mixtures comprising varying compositions and concentrations of C16:0, C18:0, and C18:1 components of each lipid class deviated $<20 \%(n=351)$ from the respective target concentrations. Limits of decision were determined to $0.3-0.8 \mathrm{mg} / \mathrm{L}$ and limits of quantitation to $0.8-1.7 \mathrm{mg} / \mathrm{L}$, expressed as $\mathrm{C} 16: 0$ representatives. Application of the method to various $\mathrm{E} 471$ emulsifiers provided detailed data on their chemical compositions, and calculated FA compositions matched very well those determined by common methods such as gas chromatography with flame ionization detection.
\end{abstract}

Keywords E 471 food emulsifiers · Monoacylglycerols · Diacylglycerols · Triacylglycerols · Fatty acids · Reversed-phase high-performance liquid chromatography-mass spectrometry (RP HPLC-MS)

\section{Introduction}

Mono- and diacylglycerols (MG/DG) of fatty acids (FA) are food additives with the E number 471 that are used due to their surface-active characteristics as emulsifiers in various food to regulate and stabilize techno-functional properties. According to Commission Regulation (EU) No 231/2012, E 471 emulsifiers are, by definition, MG and DG of FA that "consist of mixtures of glycerol mono-, di- and triesters of fatty acids occurring in food oils and fats. They may contain

Claudia Oellig

claudia.oellig@uni-hohenheim.de

1 Department of Food Chemistry and Analytical Chemistry (170a), Institute of Food Chemistry, University of Hohenheim, Garbenstraße 28, 70599 Stuttgart, Germany small amounts of free fatty acids and glycerol" [1]. Moreover, the amounts of MG and DG in the emulsifier must not be less than 70\% [1]. As per Regulation (EC) No 1333/2008 on food additives, E 471 emulsifiers are allowed to be added without a maximum level, i.e., quantum satis [2], to many foodstuffs, e.g., cream and cream powder products, jam and similar products, or pasta. However, for some products, such as food for babies and infants, maximum levels are set [2].

Usually, E 471 emulsifiers are technically produced by transesterification of triacylglycerols (TG) or by esterification of FA with glycerol. Both reactions are scarcely controllable, resulting in products comprising mixtures of MG, DG, but also glycerol, TG, FA, and further residues from the production [3]. Despite the fact that MG can be enriched by molecular distillation to contents $>95 \%$ [3], E 471 emulsifiers are still not defined substances but 
complex mixtures and differ in composition depending upon the producer.

The addition of food emulsifiers to aerosol whipping cream, desserts, or ice cream often takes place for stabilizing, adjusting, or improving techno-functional properties such as viscosity or foam consistency [3]. Due to the widely varying and often unknown composition, however, the emulsifiers and their dosage are frequently chosen empirically. Since it is known that compositional variations can affect the food's techno-functional properties, as recently shown for aerosol whipping cream [4], the analysis of the emulsifier's composition and its relation to the desired properties in foodstuffs is of high interest to guarantee a consistently high food quality.

Various methods are available for the analysis of MG, DG, TG, and FA. On the one hand, analysis by high-performance liquid chromatography (HPLC) [5-8], often coupled with detection by mass spectrometry (MS) [9-14], was applied. On the other hand, the lipid classes were analyzed after derivatization by gas chromatography (GC) with flame ionization or MS detection [15-18]. Commonly, FA were analyzed as methyl esters by GC with flame ionization detection (FID) [19, 20]. Mostly, however, these methods did not target all lipid classes mentioned at once. A method by HPLC coupled with a quadrupole time-of-flight tandem mass spectrometer via lectrospray ionization ESI-Q-ToF) was reported for the simultaneous analysis of free FA and acylglycerols, and was successfully applied to characterize the lipid composition of lipid-containing samples including dairy samples [21]. Moreover, a screening approach applying high-performance thin-layer chromatography (HPTLC), a technique that offers the analysis of multiple samples in parallel, provided a simple and rapid method for the characterization of E 471 emulsifiers by separation of all lipid classes [22]. The HPTLC approach included a response factor (RF) system for the quantitation of the individual lipid classes as sums [22].

In the present study, a method for the analysis of the lipid classes with a relatively simple and low-cost HPLC-MS system applying a single quadrupole should be developed to provide an approach that can be used by laboratories equipped with this more common technique. Moreover, reversed-phase (RP) chromatography should offer the separation of MG, DG, $\mathrm{TG}$, and FA in a single run, with the positional isomers of MG and DG also being separated, while mass spectrometry should provide sensitive and selective detection of the analytes. An additional objective of this study should be the development of a quantitation strategy based on RF allowing the determination of all analytes with only one representative of each lipid class for calibration. Finally, the composition of different MG and MG/DG emulsifiers from the market were studied by the newly developed method.

\section{Materials and methods}

\section{Chemicals and materials}

Acetonitrile (ACN, ultragradient grade for HPLC, min. 99.9\%, Chemsolute) was from Th. Geyer (Renningen, Germany) and ammonium formate $\left(\mathrm{NH}_{4} \mathrm{HCOO}\right.$, for LC-MS) was from Fisher Scientific (Schwerte, Germany). tert-Butyl methyl ether (TBME, $\geq 99.8 \%$, for HPLC, Chromasolv), formic acid ( $\mathrm{HCOOH}, \sim 98 \%$, for LC-MS), and iso-propanol ( $\geq 99.9 \%$, LC-MS, Chromasolv) were obtained from Sigma-Aldrich (Steinheim, Germany) and ethanol (absolute, $>99.7 \%$, gradient grade for HPLC, HiPerSolv Chromanorm) was purchased from VWR International (Bruchsal, Germany). Lauric acid, myristic acid, palmitic acid (PA), stearic acid, palmitoleic acid, oleic acid (all analytical standard grade, $>99.5 \%$ ), 1-monolaurin, 1-monomyristin, 1-monopalmitin (1-MP), 1-monostearin, 1-monoolein (all $\geq 99 \%), 1,2$-distearin (>99\%), 1,3-diolein ( $\geq 97 \%)$, trilaurin, trimyristin, tripalmitin (TP), tristearin, and triolein (all > 99\%) were from Sigma-Aldrich. 2-Monomyristin, 2-monopalmitin (2-MP), 2-monostearin, 2-monoolein (all > 95\%), 1,2-dilaurin (>98\%), 1,2-dimyristin, 1,2-dipalmitin (1,2-DP), 1,3-dilaurin, 1,3-dimyristin, 1,3-dipalmitin (1,3-DP), and 1,3-distearin (all > 99\%) were purchased from Larodan (Malmö, Sweden). Nucleodur Gravity-SB C18 column $(150 \mathrm{~mm} \times 3 \mathrm{~mm}, 3 \mu \mathrm{m})$ was from Macherey-Nagel (Düren, Germany). Several E 471 emulsifiers (distilled MG and MG/DG emulsifiers) were provided from different producers.

\section{Standard solutions}

TBME was used as solvent for the preparation of all standard stock solutions and all dilutions. Individual stock solutions of the lipid classes were prepared at a concentration of $500 \mathrm{mg} / \mathrm{L}$ each, resulting in six stock solutions for FA, five stock solutions for 1-MG, four stock solutions for 2-MG, four stock solutions for 1,2-DG, five stock solutions for 1,3-DG, and five stock solutions for TG (29 standard stock solutions in total, Tables 1 and 2). Standard mix solutions, calibration standards, and solutions for the validation of the quantitation strategy were prepared by respective mixing and diluting of the stock solutions (see below).

\section{Standard mix solutions for the determination of response factors (RF)}

To determine the RF, both lipid class-specific standard mix solutions for each lipid class (six lipid classes, fatty acids C12:0-C18:1) and standard mix solutions containing all analytes (total standard mix, 29 analytes) were prepared. 
Table 1 Response factors (RF) of fatty acids (FA) and 1- and 2-monoacylglycerols (1- and 2-MG) with corresponding relative standard deviations (RSD) and the respective $\mathrm{m} / \mathrm{z}$ values of the extracted ions, analyzed in $\mathrm{ESI}^{-}$

\begin{tabular}{|c|c|c|c|c|c|}
\hline Lipid class & Substance & Peak no. ${ }^{\mathrm{a}}$ & $m / z$ & $\mathrm{RF}^{\mathrm{b}}$ & $\mathrm{RSD}^{\mathrm{b}}$ \\
\hline \multirow[t]{6}{*}{ FA } & Lauric acid & 1 & $199^{\mathrm{c}}$ & 1.4 & 15.5 \\
\hline & Myristic acid & 3 & $227^{\mathrm{c}}$ & 1.1 & 10.7 \\
\hline & Palmitic acid & 5 & $255^{\mathrm{c}}$ & 1.0 & $-{ }^{\mathrm{d}}$ \\
\hline & Stearic acid & 8 & $283^{c}$ & 0.6 & 13.1 \\
\hline & Palmitoleic acid & 3 & $253^{\mathrm{c}}$ & 0.4 & 10.6 \\
\hline & Oleic acid & 5 & $281^{\mathrm{c}}$ & 0.3 & 6.2 \\
\hline \multirow[t]{5}{*}{ 1-MG } & 1-Monolaurin & 1 & $319^{\mathrm{e}}$ & 3.1 & 21.7 \\
\hline & 1-Monomyristin & 3 & $347^{\mathrm{e}}$ & 2.1 & 19.2 \\
\hline & 1-Monopalmitin & 5 & $375^{\mathrm{e}}$ & 1.0 & $-{ }^{\mathrm{d}}$ \\
\hline & 1-Monostearin & 7 & $403^{e}$ & 1.1 & 7.0 \\
\hline & 1-Monoolein & 5 & $401^{\mathrm{e}}$ & 0.4 & 8.4 \\
\hline \multirow[t]{4}{*}{ 2-MG } & 2-Monomyristin & 2 & $347^{\mathrm{e}}$ & 0.9 & 17.4 \\
\hline & 2-Monopalmitin & 4 & $375^{\mathrm{e}}$ & 1.0 & $-{ }^{\mathrm{d}}$ \\
\hline & 2-Monostearin & 6 & $403^{e}$ & 0.4 & 7.9 \\
\hline & 2-Monoolein & 4 & $401^{\mathrm{e}}$ & 0.3 & 9.2 \\
\hline
\end{tabular}

${ }^{\mathrm{a}}$ For the respective chromatogram, see Fig. 1

${ }^{b} \mathrm{RF}$ related to the respective $\mathrm{C} 16: 0$ representatives determined from lipid class-specific standard mixes and total standard mixes with RSD

[\%] at concentrations of $2.5-10 \mathrm{mg} / \mathrm{L}$ for FA and $1-\mathrm{MG}(n=24)$ and $1-10 \mathrm{mg} / \mathrm{L}$ for $2-\mathrm{MG}(n=32)$, respectively

${ }^{\mathrm{c}}$ Refers to $m / z$ of $[\mathrm{M}-\mathrm{H}]^{-}$

${ }^{\mathrm{d}}$ Reference substance, no RSD calculable

${ }^{\mathrm{e}}$ Refers to $\mathrm{m} / \mathrm{z}$ of $[\mathrm{M}+\mathrm{HCOO}]^{-}$

Both standard mix solutions had concentrations of $0.5,1$, $2.5,5$, and $10 \mathrm{mg} / \mathrm{L}$, respectively.

\section{Calibration standards}

Calibration standards contained only the $\mathrm{C} 16: 0$ representatives of each lipid class, i.e., PA, 1- and 2-MP, 1,2- and 1,3-DP, and TP. To determine limits of decision and quantitation, calibration standards at concentrations from 0.5 to $6.5 \mathrm{mg} / \mathrm{L}$ in steps of $0.5 \mathrm{mg} / \mathrm{L}$ were evaluated, and limits of decision and quantitation were determined according to the protocol of the DIN 32645 calibration graph method (coverage factor $k=3$, confidence level 99\%) [23]. Concentrations of calibration standards for the analysis of emulsifiers were $0.5,1,2,5$, and $10 \mathrm{mg} / \mathrm{L}$.

\section{Solutions for validation of the response factor (RF) quantitation strategy}

For the validation of the RF quantitation strategy, solutions containing either $\mathrm{C} 16: 0$ and $\mathrm{C} 18: 0$ representatives or $\mathrm{C} 16: 0$ and $\mathrm{C} 18: 1$ representatives of all lipid classes (FA, 1- and 2-MG, 1,2- and 1,3-DG, and TG) in both varying
Table 2 Response factors (RF) of 1,2- and 1,3-diacylglycerols (1,2and 1,3-DG) and triacylglycerols (TG) with corresponding relative standard deviations (RSD) and the respective $\mathrm{m} / \mathrm{z}$ values of the extracted ions, analyzed in $\mathrm{ESI}^{+}$(in case of two extracted $\mathrm{m} / \mathrm{z}$, the sum of the peak areas was used for calculations)

\begin{tabular}{|c|c|c|c|c|c|}
\hline Lipid class & Substance & Peak no. $^{\mathrm{a}}$ & $\mathrm{m} / \mathrm{z}$ & $\mathrm{RF}^{\mathrm{b}}$ & $\mathrm{RSD}^{\mathrm{b}}$ \\
\hline \multirow[t]{5}{*}{ 1,2-DG } & 1,2-Dilaurin & 10 & $\begin{array}{l}479^{\mathrm{c}} \\
474^{\mathrm{d}}\end{array}$ & 1.6 & 28.6 \\
\hline & 1,2-Dimyristin & 12 & $\begin{array}{l}535^{\mathrm{c}} \\
530^{\mathrm{d}}\end{array}$ & 1.1 & 17.5 \\
\hline & 1,2-Dipalmitin & 14 & $\begin{array}{l}592^{\mathrm{c}} \\
587^{\mathrm{d}}\end{array}$ & 1.0 & $-^{\mathrm{e}}$ \\
\hline & 1,2-Distearin & 17 & $\begin{array}{l}648^{\mathrm{c}} \\
643^{\mathrm{d}}\end{array}$ & 0.9 & 17.2 \\
\hline & 1,2-Diolein & $-{ }^{\mathrm{f}}$ & $\begin{array}{l}644^{\mathrm{c}} \\
639^{\mathrm{d}}\end{array}$ & $-^{\mathrm{f}}$ & $-{ }^{f}$ \\
\hline \multirow[t]{5}{*}{ 1,3-DG } & 1,3-Dilaurin & 9 & $\begin{array}{l}479^{\mathrm{g}} \\
439^{\mathrm{c}}\end{array}$ & 1.2 & 26.1 \\
\hline & 1,3-Dimyristin & 11 & $\begin{array}{l}535^{\mathrm{g}} \\
495^{\mathrm{c}}\end{array}$ & 1.2 & 17.1 \\
\hline & 1,3-Dipalmitin & 13 & $\begin{array}{l}552^{\mathrm{g}} \\
592^{\mathrm{c}}\end{array}$ & 1.0 & $-^{\mathrm{e}}$ \\
\hline & 1,3-Distearin & 16 & $\begin{array}{l}608^{\mathrm{g}} \\
648^{\mathrm{c}}\end{array}$ & 0.8 & 9.9 \\
\hline & 1,3-Diolein & 13 & $\begin{array}{l}604^{\mathrm{g}} \\
644^{\mathrm{c}}\end{array}$ & 0.9 & 4.6 \\
\hline \multirow[t]{5}{*}{ TG } & Trilaurin & 15 & $657^{\mathrm{d}}$ & 1.2 & 29.4 \\
\hline & Trimyristin & 18 & $741^{\mathrm{d}}$ & 1.2 & 21.5 \\
\hline & Tripalmitin & 20 & $825^{\mathrm{d}}$ & 1.0 & $-^{\mathrm{e}}$ \\
\hline & Tristearin & 21 & $909^{\mathrm{d}}$ & 1.7 & 24.7 \\
\hline & Triolein & 19 & $903^{\mathrm{d}}$ & 1.3 & 14.7 \\
\hline
\end{tabular}

${ }^{\mathrm{a}}$ For the respective chromatogram, see Fig. 1

${ }^{\mathrm{b}} \mathrm{RF}$ related to the respective $\mathrm{C} 16: 0$ representatives determined from lipid class-specific standard mixes and total standard mixes with RSD [\%] at concentrations of $0.5-10 \mathrm{mg} / \mathrm{L}(n=40)$

${ }^{\mathrm{c}}$ Refers to $\mathrm{m} / \mathrm{z}$ of $[\mathrm{M}+\mathrm{Na}]^{+}$

${ }^{\mathrm{d}}$ Refers to $m / z$ of $\left[\mathrm{M}+\mathrm{NH}_{4}\right]^{+}$

${ }^{\mathrm{e}}$ Reference substance, no RSD calculable

${ }^{\mathrm{f}}$ Standard substance was not available, coelution with peak no. 14 expected, RF was not determinable

${ }^{\mathrm{g}}$ Refers to $\mathrm{m} / \mathrm{z}$ of $\left[\mathrm{M}+\mathrm{H}-\mathrm{H}_{2} \mathrm{O}\right]^{+}$

compositions and concentrations were considered. Investigated ratios of $\mathrm{C} 16: 0$ to $\mathrm{C} 18: 0$ and $\mathrm{C} 16: 0$ to $\mathrm{C} 18: 1$, respectively, were as follows: 0:100, 25:75, 50:50, 75:25, and 100:0. The concentration of each lipid class was either $4 \mathrm{mg} / \mathrm{L}$ or $8 \mathrm{mg} / \mathrm{L}$, which, taking the ratios into account, led to concentrations of $1,2,3,4,6$, and $8 \mathrm{mg} / \mathrm{L}$ for the respective C16:0, C18:0, and C18:1 representatives, respectively. A solution containing, for example, $\mathrm{C} 16: 0$ and $\mathrm{C} 18: 0$ representatives of the lipid classes at concentrations of $4 \mathrm{mg} / \mathrm{L}$ for each lipid class and a ratio of 25:75 was composed as follows: $1 \mathrm{mg} / \mathrm{L}$ of each C16:0 component (i.e., $1 \mathrm{mg} / \mathrm{L}$ of PA, 1- and 2-MP, 1,2- and 1,3-DP, and TP) and $3 \mathrm{mg} / \mathrm{L}$ of each 
C18:0 component (i.e., $3 \mathrm{mg} / \mathrm{L}$ of stearic acid, 1 - and 2-monostearin, 1,2- and 1,3-distearin, and tristearin). A solution containing, for example, $\mathrm{C} 16: 0$ and $\mathrm{C} 18: 1$ representatives of the lipid classes at concentrations of $8 \mathrm{mg} / \mathrm{L}$ for each lipid class and a ratio of 75:25 was composed as follows: $6 \mathrm{mg} / \mathrm{L}$ of each C16:0 component (i.e., $6 \mathrm{mg} / \mathrm{L}$ of PA, 1- and 2-MP, 1,2- and 1,3-DP, and TP) and $2 \mathrm{mg} / \mathrm{L}$ of each C18:1 component (i.e., $2 \mathrm{mg} / \mathrm{L}$ of oleic acid, 1- and 2-monoolein, 1,2- and 1,3-diolein, and triolein).

\section{High-performance liquid chromatography-mass spectrometry (HPLC-MS)}

The HPLC-MS system consisted of an Agilent 1100 system (Agilent Technologies, Waldbronn, Germany) with a quaternary pump, a vacuum solvent degasser unit, a column oven, and an autosampler connected to a single quadrupole mass spectrometer (G6120, Agilent Technologies) equipped with an ESI interface. RP chromatography on a Nucleodur Gravity-SB C18 column $(150 \mathrm{~mm} \times 3 \mathrm{~mm}, 3 \mu \mathrm{m})$ was performed with $\mathrm{ACN}$ including $0.1 \% \mathrm{HCOOH}$ (eluent $\mathrm{A}$ ) and $1 \mathrm{mM}$ $\mathrm{NH}_{4} \mathrm{HCOO}$ in iso-propanol (eluent $\mathrm{B}$, prepared by dissolving $\mathrm{NH}_{4} \mathrm{HCOO}$ via ultrasonication at $65{ }^{\circ} \mathrm{C}$ for about $60 \mathrm{~min}$ ). The gradient, at a flow rate of $0.4 \mathrm{~mL} / \mathrm{min}$ and $25^{\circ} \mathrm{C}$, was as follows: $100 \% \mathrm{~A}$ (0-5 min), decreased to $80 \% \mathrm{~A}$ (5-20 $\mathrm{min})$, decreased to $25 \%$ A (20-42 min), kept constant at $25 \%$ A (42-55 min), increased to $100 \%$ A (55-60 min), and kept constant at $100 \%$ A for $5 \mathrm{~min}$, resulting in a total run time of $65 \mathrm{~min}$. The injection volume was generally $4 \mu \mathrm{L}$. Measurement was performed in the $\mathrm{ESI}^{-}$mode from 0 to $9.15 \mathrm{~min}$ for the analysis of FA and $\mathrm{MG}$, and in the $\mathrm{ESI}^{+}$mode from 9.15 to 65 min for the analysis of DG and TG. Total ion current chromatograms were recorded in scan mode over a mass range of $m / z, 160-420$ for $\mathrm{ESI}^{-}$and $m / z$ 200-960 for $\mathrm{ESI}^{+}$, respectively. Ionization was performed applying a fragmentor voltage of $110 \mathrm{~V}$ in the $\mathrm{ESI}^{-}$mode at a gain of 5 , and a fragmentor voltage of $150 \mathrm{~V}$ in the $\mathrm{ESI}^{+}$ mode at a gain of 3 . Threshold was 100 and the step size 0.1 for both modes. Spray chamber parameters were as follows: drying gas temperature $340{ }^{\circ} \mathrm{C}$, drying gas flow rate $10 \mathrm{~L} / \mathrm{min}$, nebulizer gas pressure $40 \mathrm{psig}$, quadrupole temperature $100{ }^{\circ} \mathrm{C}$, and capillary voltage $5 \mathrm{kV}$. All instruments were controlled by OpenLAB CDS ChemStation C.01.09 software (Agilent Technologies). The data were evaluated employing the software MassHunter (B.08.00, Agilent Technologies) by extracting the respective ion traces (for $m / z$ values see Tables 1 and 2 and Tables $\mathrm{S} 1$ and $\mathrm{S} 2$ in the Online Resource) after translating the data with the LC/SQ ChemStation to MassHunter Translator (B.04.00, B481.16, Agilent Technologies). Data evaluation, calculation, and visualization were performed by Excel 2016 (Microsoft Corporation; Redmond, WA, USA; Microsoft Professional Plus
2016) and OriginPro (OriginLab Corporation, Northampton, MA, USA; version: OriginPro 2019).

\section{Analysis of E 471 emulsifiers}

The analysis comprised ten E 471 emulsifier samples provided by different manufacturers, including six distilled MG and four MG/DG emulsifiers. Determination was performed by simply dissolving the emulsifiers in a mixture of TBME/ ethanol $(1: 1, v / v)$ and diluting with TBME to concentrations of 5-2000 $\mathrm{mg} / \mathrm{L}$ prior to HPLC-MS analysis.

\section{Results and discussion}

\section{High-performance liquid chromatography-mass spectrometry (HPLC-MS)}

\section{Chromatography}

The objective of the method development was the chromatographic separation and simultaneous analysis of C12:0-C18:1 representatives of the lipid classes FA, MG, $\mathrm{DG}$, and TG, which represent the main components of $\mathrm{E} 471$ emulsifiers, including the separation of positional isomers.

The analysis of glycerides by RP HPLC was commonly performed with ACN [6, 9, 12] or methanol as eluents [5, $10,11]$, when often gradient elution with iso-propanol [5, 6] or mixtures of $i$ so-propanol and $n$-hexane [6] was applied. In some studies, multiple columns were coupled to obtain a suitable separation of the analytes $[6,9,12]$, which, however, led to long chromatographic analyses (> $100 \mathrm{~min}$ ). One study presented an HPLC-MS approach for the analysis of emulsifiers of the types E 471 and E 472 (esters of MG and DG) but focused only on MG and DG and did not report the run time [10]. Another HPLC-MS approach applying RP HPLC coupled with Q-ToF-MS via ESI provided the simultaneous analysis of FA, MG, DG, and TG in oils and lipidcontaining products in a single chromatographic run with gradient elution using methanol/water and iso-propanol [21]. Although short chromatographic run times were achieved with this method, derivatization for the determination of FA is needed and the method is based on the use of a ToF-MS which is not necessarily available in every laboratory [21].

In the present study, different spherical phase RP columns with slightly different carbon content and selectivity of different manufacturers were part of the evaluation, while gradient elution was performed with methanol and ACN, respectively, as eluent A and iso-propanol as eluent B. However, inadequate separation of the positional isomers of MG and DG was obtained with methanol as eluent A, while ACN as eluent A offered the separation of these positional isomers. Moreover, the addition of $n$-hexane (as suggested 
in [6]) to eluent B was investigated but did not lead to any improvements. To increase the efficiency of ESI, additives were investigated. An addition of $0.1 \% \mathrm{HCOOH}$ to eluent A and $1 \mathrm{mM} \mathrm{NH}_{4} \mathrm{HCOO}$ to eluent $\mathrm{B}$ showed promising intensities for all lipid classes and was therefore used for further optimization. Additionally, the chromatographic separation of the positional isomers of $\mathrm{MG}$ and DG with a run time as short as possible was intended. Therefore, different gradients and temperatures $\left(25,30\right.$, and $\left.35^{\circ} \mathrm{C}\right)$ were tested. Finally, chromatography was performed at $25{ }^{\circ} \mathrm{C}$ with a total run time of $65 \mathrm{~min}$ and the final gradient given in the materials and methods section (see above, HPLC-MS), leading to the elution of FA and MG before DG and TG. Coelution was obtained for instance for the C16:0 and C18:1 representatives of FA, MG, and DG (Tables 1 and 2), but positional isomers of MG and DG were well separated, which allowed the reliable mass-selective detection of all investigated C12:0-C18:1 representatives of the six lipid classes in a single run (Fig. 1). As shown in a previous study, variances of different components of emulsifiers can have an effect on the techno-functional properties, e.g., varying contents of 1,3-DG affected the drainage of aerosol whipping cream [24]. By separation of positional isomers of MG and DG, a comprehensive analysis of the emulsifiers is given, which thus will provide the possibility to relate the effects of single emulsifier constituents to techno-functional properties more specifically.

\section{Mass-selective detection}

Evaluation and optimization of the ESI parameters for the detection of the analytes were performed by flow injection analysis. Fragmentor voltage, capillary voltage, and nebulizer gas pressure were optimized regarding the sensitivity by direct injection of $5 \mu \mathrm{L}$ of individual standard solutions of the C18:0 representatives of each lipid class at concentrations of $2.5 \mathrm{mg} / \mathrm{L}$. For this purpose, different eluents and eluent compositions were used. To optimize the parameters for FA and MG, only eluent A, for DG, a mixture of eluent $\mathrm{A}$ and $\mathrm{B}$ at a ratio of 50:50 $(\mathrm{v} / \mathrm{v})$, and for TG, a mixture of eluent A and B at a ratio of 30:70 $(v / v)$ were investigated. Final parameters are given in the materials and methods section (see above, HPLC-MS). ESI ${ }^{-}$offered the highest sensitivity for FA and MG, while $\mathrm{ESI}^{+}$provided the highest signal intensity for DG and TG. The separation and elution order of the lipid classes allowed their detection in two time windows starting with $\mathrm{ESI}^{-}$for FA and MG and switching to $\mathrm{ESI}^{+}$for DG and TG after the elution of the last FA, i.e., stearic acid (switch at $9.15 \mathrm{~min}$ ). Tables 1 and 2 list the $\mathrm{m} / \mathrm{z}$ values that delivered both highest repeatability of results and lowest relative standard deviations (RSD), and which were used for quantitation of the analytes. In $\mathrm{ESI}^{-}$, deprotonated molecules and formate adducts were best suited, while in $\mathrm{ESI}^{+}$sodium and ammonium adducts and protonated molecules followed by water elimination were used. For DG, the sum of two signals, i.e., $[\mathrm{M}+\mathrm{Na}]^{+}$and $\left[\mathrm{M}+\mathrm{NH}_{4}\right]^{+}$for $1,2-\mathrm{DG}$ and $\left[\mathrm{M}+\mathrm{H}-\mathrm{H}_{2} \mathrm{O}\right]^{+}$and $[\mathrm{M}+\mathrm{Na}]^{+}$for $1,3-\mathrm{DG}$, was used since this provided highest repeatability of the results. Thereby, it was observed that the ammonium adducts were more prominent for 1,2-DG than for 1,3-DG, exemplarily shown for the C16:0 and C18:0 DG, analyzed in a solution containing the $\mathrm{C} 16: 0$ and $\mathrm{C} 18: 0$ representatives of all lipid classes (Fig. 2a and b). For 1,3-DG, in contrast, the dominant ion was $\left[\mathrm{M}+\mathrm{H}-\mathrm{H}_{2} \mathrm{O}\right]^{+}$.

\section{Response factors (RF)}

A strategy based on RF and requiring only six standard substances (one for each lipid class) for the quantitation of the considered individual analytes (see Tables 1 and 2) has been developed. Similar to the quantitation system of a recently developed screening approach by HPTLC, which required only one standard substance for calibration and quantitated lipid classes with different FA as the sums [22], the RF strategy of the HPLC-MS method applied a standard mix (calibration standard) containing the $\mathrm{C} 16: 0$ representatives

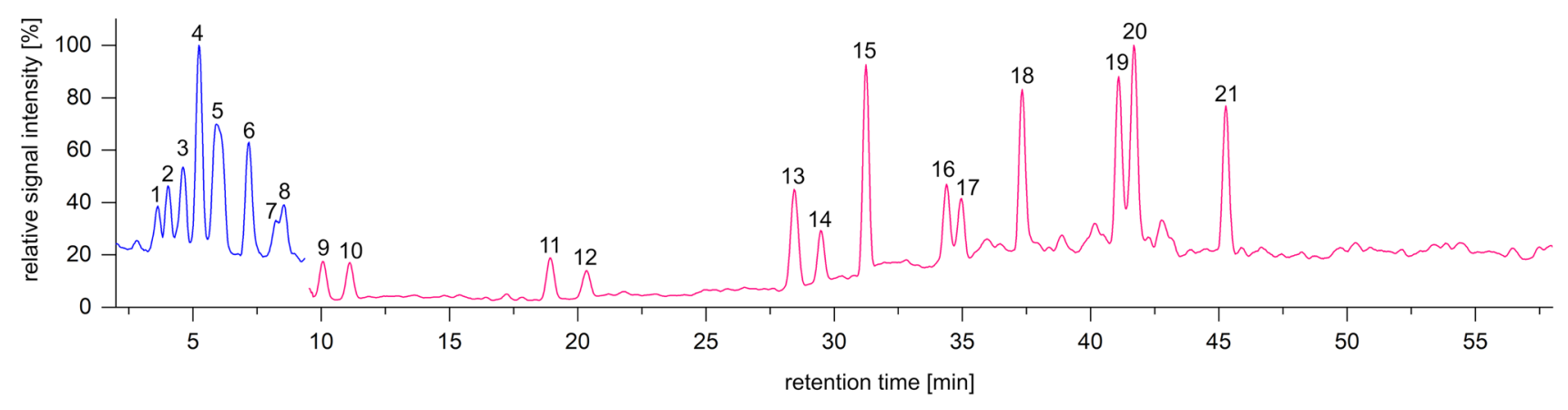

Fig. 1 HPLC-MS chromatogram of a total standard mix, each component at a concentration of $5 \mathrm{mg} / \mathrm{L}$ ( 29 analytes eluting in 21 peaks due to partial coelution, fatty acids $\mathrm{C} 12: 0-\mathrm{C} 18: 1$, lipid classes FA,
1- and 2-MG, 1,2- and 1,3-DG, and TG). For peak assignments and coelutions, see Tables 1 and 2 
a

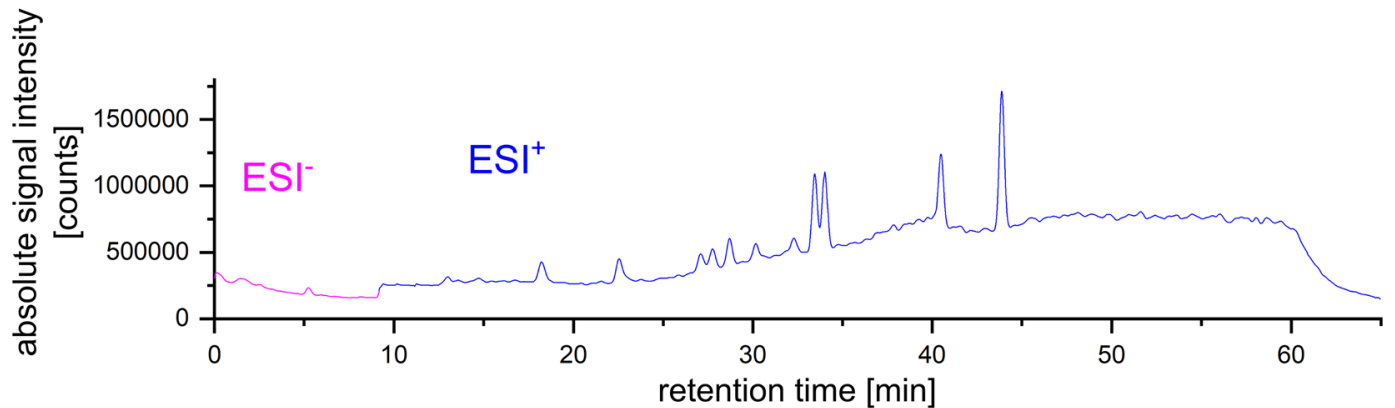

b dipalmitin

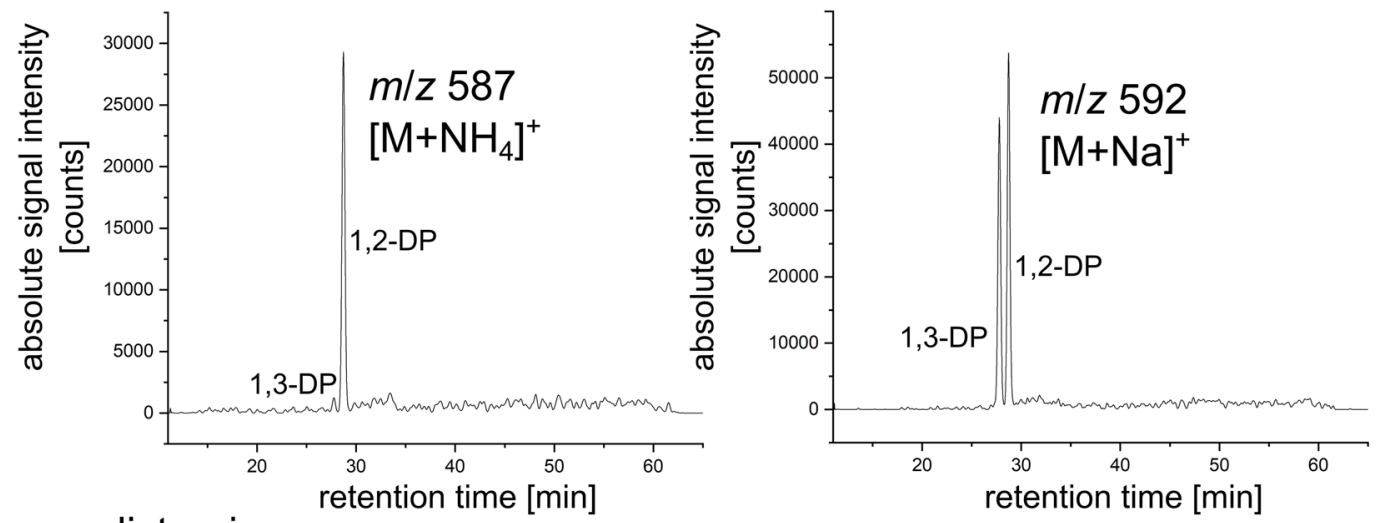

distearin
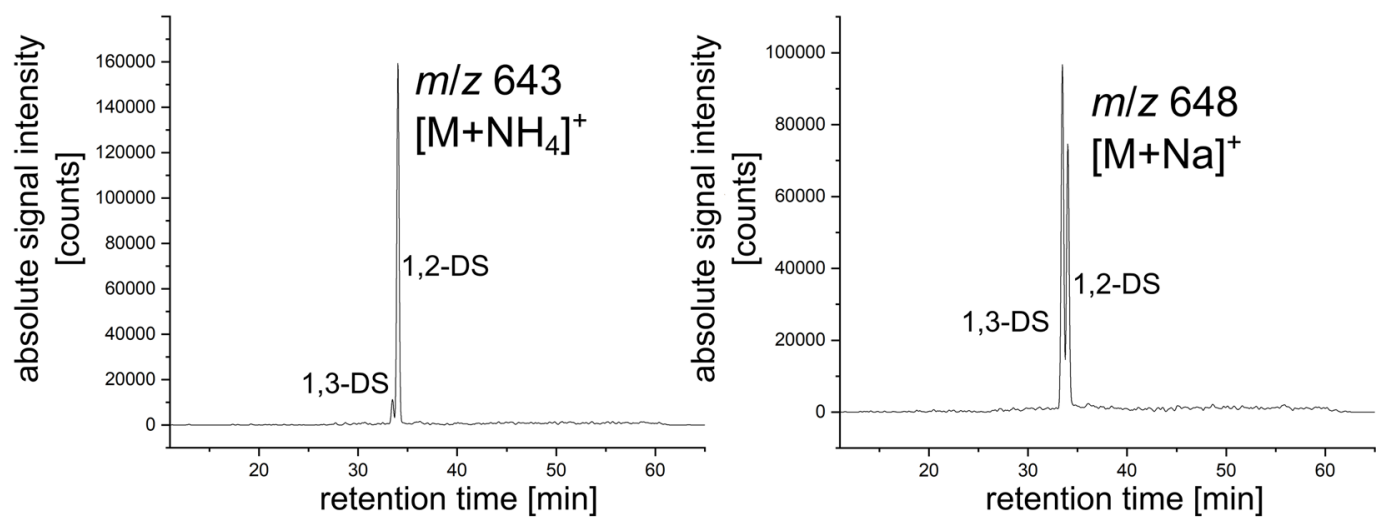

C

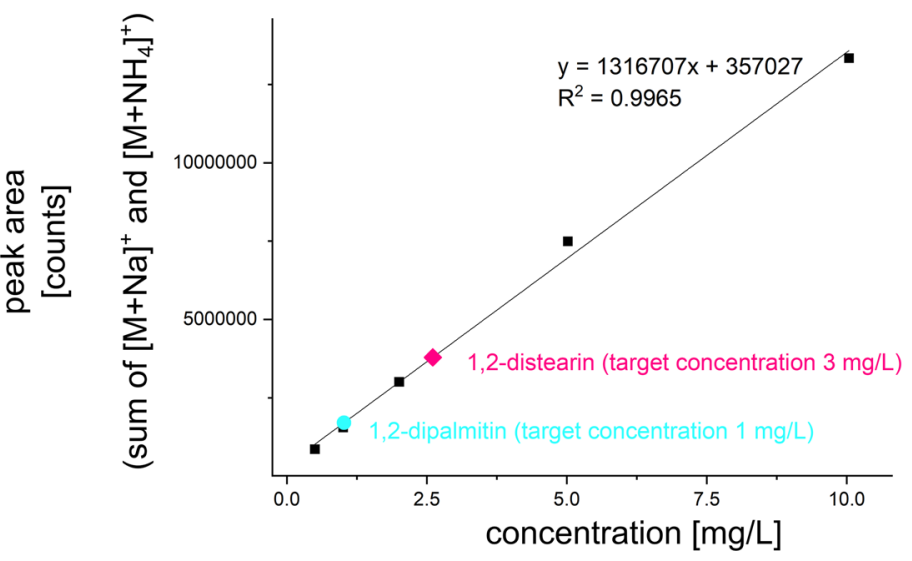


4Fig. 2 HPLC-MS chromatogram (a) of a solution containing C16:0 and $\mathrm{C} 18: 0$ representatives of all lipid classes at a concentration of $4 \mathrm{mg} / \mathrm{L}$ for each lipid class at a ratio of 25:75 (corresponding to $1 \mathrm{mg} / \mathrm{L} \mathrm{C16:0}$ and $3 \mathrm{mg} / \mathrm{L} \mathrm{C18:0)}$. Extracted ion chromatograms (b) of $\mathrm{m} / \mathrm{z}$ for dipalmitin (DP) and distearin (DS), showing the positional isomers (1,2- and 1,3-DG) chromatographically well separated. Linear calibration graph $(\mathbf{c})$ of C16:0 standard solutions $(0.5-10 \mathrm{mg} / \mathrm{L})$ including sample results for 1,2-DP (circle) and 1,2-DS (diamond) after taking the corresponding RF into account. Calibration graph $(n=1)$ was generated by OriginPro performing linear fitting, and stating standard errors for the intercept and slope, respectively, of 229,959 and 44,876 , and an adjusted $R^{2}$ of 0.9954 (standard errors were scaled with square root of reduced Chi-square)

of the six lipid classes. The RF were determined by correlating the response of a lipid representative to the response of the respective $\mathrm{C} 16: 0$ representative within the same lipid class, whereat calculation considered the absolute amount per signal (ng per peak). Due to different sensitivities of the individual lipid classes (see below, sensitivity and calibration range in the validation section), $\mathrm{RF}$ were calculated in a range of $2.5-10 \mathrm{mg} / \mathrm{L}$ for FA and 1-MG, $1-10 \mathrm{mg} / \mathrm{L}$ for 2-MG, and $0.5-10 \mathrm{mg} / \mathrm{L}$ for DG and TG, whereat both lipid class-specific standard mixes and total standard mixes were evaluated (see above, standard mix solutions for the determination of RF in the materials and methods section). Analyses were repeated three times for each concentration of lipid class-specific standard mixes and five times for each concentration of the total standard mixes $(n=351)$.

Evaluation of the results revealed the RF strategy to be well suitable for the quantitation of the different lipid class representatives in mixtures because no remarkable differences were observed between RF determined from total standard mixes and lipid class-specific standard mixes. The overall RF are shown in Tables 1 and 2, with RSD for most analytes ( 17 out of 23 values) $<20 \%$, while the others showed adequate RSD of $<30 \%$. This enabled a straightforward quantitation by considering the determined RF prior to employing the equation of calibration graphs obtained from calibration standards containing only C16:0 representatives, i.e., only six substances. Therefore, this strategy represents a simple to perform, time- and cost-efficient approach for the determination of the considered C12:0-C18:1 representatives of FA, MG, DG, and TG, without the need of redundant calibrations for each analyte.

\section{Validation}

\section{Quantitation by response factors (RF)}

To validate the RF strategy applied for quantitation, solutions of both different concentrations and compositions of C16:0 and C18:0 and of C16:0 and C18:1 representatives of the lipid classes FA, 1- and 2-MG, 1,2- and 1,3-DG, and TG were analyzed by HPLC-MS. The suitability of the RF strategy was determined by analyzing model mix solutions, as the aim of the study was the analysis of the pure, complexly composed commercial emulsifiers. The investigated representatives were chosen based on the main constituents of MG and MG/DG emulsifiers. The peak areas of the extracted total ion chromatograms (for the adducts and the $\mathrm{m} / \mathrm{z}$ values, see Tables 1 and 2 ) were corrected by the corresponding RF, allowing a simple quantitation by performing calibration with the $\mathrm{C} 16: 0$ representatives, as exemplarily shown in Fig. 2c for 1,2-DG. The analyzed solution exemplified in Fig. 2 contained the C16:0 and C18:0 representatives of all lipid classes, with each lipid class at a concentration of $4 \mathrm{mg} / \mathrm{L}$ and a ratio of C16:0 to C18:0 of 25:75 (see above, solutions for validation of the RF quantitation strategy in the materials and methods section). The determined concentrations were compared to the target concentrations and stated in percent (Table S3 in the Online Resource). The calculated concentrations correlated well with the target concentrations, with an overall correlation for all considered lipid class representatives (C16:0 and C18:0 or C16:0 and C18:1), ratios (0:100-100:0), and concentrations (1-8 mg/L) of $99 \%$, showing the applicability and the good accuracy of the RF quantitation strategy. Noticeable deviations (correlation $>130 \%$ ) were observed at a concentration of $1 \mathrm{mg} / \mathrm{L}$ for the C16:0, C18:0, and C18:1 representatives of 2-MG and at a concentration of $2 \mathrm{mg} / \mathrm{L}$ for the C18:1 representatives of FA and 1-MG, when the respective concentrations were close to the corresponding limit of quantitation. The experiments showed a good repeatability for both considered concentrations and the individual representatives. Precisions, expressed as the RSD related to the concentration, were $17 \%(n=169)$ for the $4 \mathrm{mg} / \mathrm{L}$ level and $16 \%(n=182)$ for the $8 \mathrm{mg} / \mathrm{L}$ level, while the correlations between the calculated and target concentrations for the different representatives showed a precision of $\leq 22 \%$ ( $n=184$ for C16:0, $n=91$ for $\mathrm{C} 18: 0$, and $n=76$ for $\mathrm{C} 18: 1$ ) for all considered concentrations.

\section{Sensitivity and calibration range}

The sensitivity of the method, indicated by limits of decision and quantitation, was determined according to the DIN 32645 calibration graph method [23]. For this purpose, at least five calibration standards close to the presumed limit of decision, that show linear correlation, were evaluated. The limits of decision for $\mathrm{C} 16: 0$ representatives were determined to $0.3-0.8 \mathrm{mg} / \mathrm{L}$ and the limits of quantitation to $0.8-1.7 \mathrm{mg} / \mathrm{L}$, respectively (Table $\mathrm{S} 4$ in the Online Resource). These data correspond to limits of decision between 0.3 and $3.3 \mathrm{mg} / \mathrm{L}$ and limits of quantitation between 0.5 and $6.1 \mathrm{mg} / \mathrm{L}$ for all investigated analytes after considering the RF. 
Based on the sensitivity, and taking the concentrations for which RF were determined into account (see above, Response factors (RF) in the result section and footnotes in Tables 1 and 2), calibration ranges for the analysis of emulsifiers were set to $2-10 \mathrm{mg} / \mathrm{L}$ for FA and $1-\mathrm{MG}, 1-10 \mathrm{mg} / \mathrm{L}$ for 2-MG, and 0.5-10 mg/L for 1,2-DG, 1,3-DG, and TG. Calibrations for PA, 1- and 2-MP, and 1,2- and 1,3-DP showed a linear correlation with high coefficients of determination $\left(R^{2}=0.9941\right.$ for $\mathrm{PA}, R^{2}=0.9932$ for $1-\mathrm{MP}, R^{2}=0.9958$ for 2-MP, $R^{2}=0.9934$ for $1,2-\mathrm{DP}$, and $R^{2}=0.9910$ for $1,3-\mathrm{DP}$ $\mathrm{RSD}<0.6 \%$ each, $n=2$ ), while for $\mathrm{TG}$, a polynomic relation, also with a high coefficient of determination $\left(R^{2}=0.9996\right.$, $\mathrm{RSD}<0.04 \%, n=2$ ), showed a better correlation.

\section{Analysis of E 471 emulsifiers}

Different E 471 emulsifiers were analyzed by the newly developed HPLC-MS method, including six distilled MG emulsifiers and four MG/DG emulsifiers. Dissolved emulsifiers were studied in a wide concentration range (5-2000 mg/L) to get comprehensive knowledge of their compositions. In case of high concentrations with presumably high amounts of MG, detection only took place in the $\mathrm{ESI}^{+}$mode to protect the mass spectrometer from high analyte loads. After considering the corresponding RF, quantitation was performed with calibration functions of the C16:0 representatives. Contents of individual FA, 1- and 2-MG, 1,2- and 1,3-DG, and TG were calculated as a percentage, additionally taking the previously determined correlation between the calculated and the target concentrations into account (Table S3 in the Online Resource). To determine the contents of 1,2-diolein, the RF and the correlations determined for 1,3-diolein were used since no standard substance was available.

The results for the different lipid classes of the investigated distilled MG and MG/DG emulsifiers are given in Tables 3 and 4 (for detailed values, see Tables S5-14 in the Online Resource). The analysis of the samples confirmed the suitability of the developed HPLC-MS method in combination with the RF quantitation strategy for the target analytes, indicated by a good precision of RSD $<20 \%$ for all determinations of the individual analytes. However, during sample evaluation and comparison of the results with specified data of the manufacturers, several clear differences were found for some emulsifiers. On the one hand, deviations could be explained by the raw material, i.e., the vegetable oils from which the emulsifiers were manufactured and, thus, their FA compositions that can vary between different batches of the product. On the other hand, the developed method did initially not consider DG and TG that contain different FA (also named "mixed DG and TG"). However, the presence of such DG and TG is possible and quite likely due to the hardly controllable reactions during the production of the emulsifiers. In addition, rearrangements during storage of emulsifiers are known [24]. These aspects were therefore also part of the following discussion.

The raw materials of the emulsifiers IV and V were two types of sunflower oil (not or partially hydrogenated) and the raw material of emulsifier III was rapeseed oil (partially hydrogenated), thus also comprising a noticeable amount of linoleic acid (C18:2), of which representatives no RF were available. For an estimation of these contents, the amounts of these derivatives (see Table S1 for detailed information on $\mathrm{m} / \mathrm{z}$ values in the Online Resource) were calculated under
Table 3 Determined contents [\%] of fatty acids (FA), monoacylglycerols (MG), diacylglycerols (DG), and triacylglycerols (TG) in different distilled $\mathrm{MG}$ emulsifiers of the type $\mathrm{E} 471$ by HPLC-MS. Specified values according to specification sheet/certificate of analysis of manufacturers are given in brackets (ns, not specified). For more detailed data, see Tables S5-10 in the Online Resource

\begin{tabular}{|c|c|c|c|c|c|c|}
\hline Emulsifier & I & II & III & IV & V & VI \\
\hline FA & $\begin{array}{l}\mathrm{nd}^{\mathrm{a}} \\
(\mathrm{ns})\end{array}$ & $\begin{array}{l}\mathrm{nd}^{\mathrm{a}} \\
(\mathrm{ns})\end{array}$ & $\begin{array}{l}2.1 \\
\text { (ns) }\end{array}$ & $\begin{array}{l}\mathrm{nd}^{\mathrm{a}} \\
\text { (ns) }\end{array}$ & $\begin{array}{l}\mathrm{nd}^{\mathrm{a}} \\
\text { (ns) }\end{array}$ & $\begin{array}{l}\mathrm{nd}^{\mathrm{a}} \\
\text { (ns) }\end{array}$ \\
\hline $\begin{array}{l}\text { Sum MG } \\
\text { Sum } \mathrm{MG}^{\mathrm{b}}\end{array}$ & $\begin{array}{l}94.8 \\
94.8 \\
(\geq 90)\end{array}$ & $\begin{array}{l}85.4 \\
85.4 \\
(\geq 90)\end{array}$ & $\begin{array}{l}89.5 \\
92.8 \\
(\geq 90)\end{array}$ & $\begin{array}{l}49.7 \\
97.2 \\
(97)\end{array}$ & $\begin{array}{l}87.7 \\
97.1 \\
(\geq 90)\end{array}$ & $\begin{array}{l}93.4 \\
93.4 \\
(\geq 90)\end{array}$ \\
\hline $\begin{array}{l}\text { Sum DG } \\
\text { Sum } D^{b}\end{array}$ & $\begin{array}{l}0.9 \\
0.9 \\
(\mathrm{~ns})\end{array}$ & $\begin{array}{l}0.8 \\
0.8 \\
(\mathrm{~ns})\end{array}$ & $\begin{array}{l}1.2 \\
1.2 \\
\text { (ns) }\end{array}$ & $\begin{array}{l}0.3 \\
1.2 \\
\text { (ns) }\end{array}$ & $\begin{array}{l}1.8 \\
1.8 \\
\text { (ns) }\end{array}$ & $\begin{array}{l}1.0 \\
1.0 \\
\text { (ns) }\end{array}$ \\
\hline TG & $\begin{array}{l}\mathrm{nd}^{\mathrm{a}} \\
(\mathrm{ns})\end{array}$ & $\begin{array}{l}\mathrm{nd}^{\mathrm{a}} \\
(\mathrm{ns})\end{array}$ & $\begin{array}{l}<\mathrm{LOQ}^{\mathrm{c}} \\
(\mathrm{ns})\end{array}$ & $\begin{array}{l}\mathrm{nd}^{\mathrm{a}} \\
(\mathrm{ns})\end{array}$ & $\begin{array}{l}\mathrm{nd}^{\mathrm{a}} \\
(\mathrm{ns})\end{array}$ & $\begin{array}{l}<\mathrm{LOQ}^{\mathrm{c}} \\
(\mathrm{ns})\end{array}$ \\
\hline $\begin{array}{l}\text { Total } \\
\text { Total }^{\text {b }}\end{array}$ & $\begin{array}{l}95.7 \\
95.7\end{array}$ & $\begin{array}{l}86.2 \\
86.2\end{array}$ & $\begin{array}{l}92.8 \\
96.2\end{array}$ & $\begin{array}{l}50.1 \\
98.4\end{array}$ & $\begin{array}{l}89.5 \\
98.9\end{array}$ & $\begin{array}{l}94.4 \\
94.4\end{array}$ \\
\hline
\end{tabular}

${ }^{\mathrm{a}}$ Not detectable, $<$ limit of decision

${ }^{\mathrm{b}}$ Including amounts of $\mathrm{C} 18: 2$ representatives, calculated with $\mathrm{RF}$ and correlations of the C18:1 representatives. No C18:2 representatives of MG were detected in emulsifiers I, II, and VI. C18:2 representatives of DG were only detected in emulsifier IV

${ }^{\mathrm{c}}$ Limit of quantitation 
Table 4 Determined contents [\%] of fatty acids (FA), monoacylglycerols (MG), diacylglycerols (DG), and triacylglycerols (TG) in different MG/DG emulsifiers of the type E 471 by HPLC-MS. Specified values according to specification sheet/certificate of analysis of manufacturers are given in brackets (ns, not specified). For more detailed data, see Tables S11-14 in the Online Resource

\begin{tabular}{|c|c|c|c|c|}
\hline Emulsifier & VII & VIII & IX & $\mathrm{X}$ \\
\hline FA & $\begin{array}{l}\mathrm{nd}^{\mathrm{a}} \\
(\mathrm{ns})\end{array}$ & $\begin{array}{l}7.1 \\
\text { (ns) }\end{array}$ & $\begin{array}{l}1.9 \\
\text { (ns) }\end{array}$ & $\begin{array}{l}2.4 \\
\text { (ns) }\end{array}$ \\
\hline $\begin{array}{l}\text { Sum MG } \\
\text { Sum } \mathrm{MG}^{\mathrm{b}}\end{array}$ & $\begin{array}{l}38.7 \\
45.0 \\
(32-52)\end{array}$ & $\begin{array}{l}30.6 \\
30.6 \\
(\geq 30)\end{array}$ & $\begin{array}{l}52.7 \\
52.7 \\
(\geq 60)\end{array}$ & $\begin{array}{l}64.4 \\
64.4 \\
(64.0)\end{array}$ \\
\hline $\begin{array}{l}\text { Sum DG } \\
\text { Sum } \text { DG }^{\mathrm{c}}\end{array}$ & $\begin{array}{l}24.5 \\
24.5 \\
(30-50)\end{array}$ & $\begin{array}{l}16.2 \\
31.1 \\
(n s)\end{array}$ & $\begin{array}{l}12.2 \\
22.0 \\
(\mathrm{~ns})\end{array}$ & $\begin{array}{l}13.5 \\
23.9 \\
(30.6)\end{array}$ \\
\hline TG & $\begin{array}{l}2.7 \\
(5-20)\end{array}$ & $\begin{array}{l}2.1 \\
\text { (ns) }\end{array}$ & $\begin{array}{l}0.5 \\
\text { (ns) }\end{array}$ & $\begin{array}{l}0.5 \\
(3.1)\end{array}$ \\
\hline $\begin{array}{l}\text { Total } \\
\text { Total }^{\mathrm{b}, \mathrm{c}}\end{array}$ & $\begin{array}{l}66.0 \\
72.2^{\mathrm{b}}\end{array}$ & $\begin{array}{l}56.0 \\
70.9^{\mathrm{c}}\end{array}$ & $\begin{array}{l}67.3 \\
77.0^{c}\end{array}$ & $\begin{array}{l}80.8 \\
91.2^{\mathrm{c}}\end{array}$ \\
\hline
\end{tabular}

${ }^{a}$ Not detectable, $<$ limit of decision

${ }^{\mathrm{b}}$ Including amounts of $\mathrm{C} 18: 2$ representatives, calculated with RF and correlations of the $\mathrm{C} 18: 1$ representatives. No C18:2 representatives were detected for emulsifiers VIII, IX, and X

${ }^{c}$ Including amounts of mixed DG that contain C16:0 and C18:0 FA, calculated with mean RF and correlations of 1,2-DG and 1,3-DG of DG containing exclusively C16:0 or C18:0, respectively. No mixed DG with C16:0 and C18:0 FA were detected in emulsifier VII

a

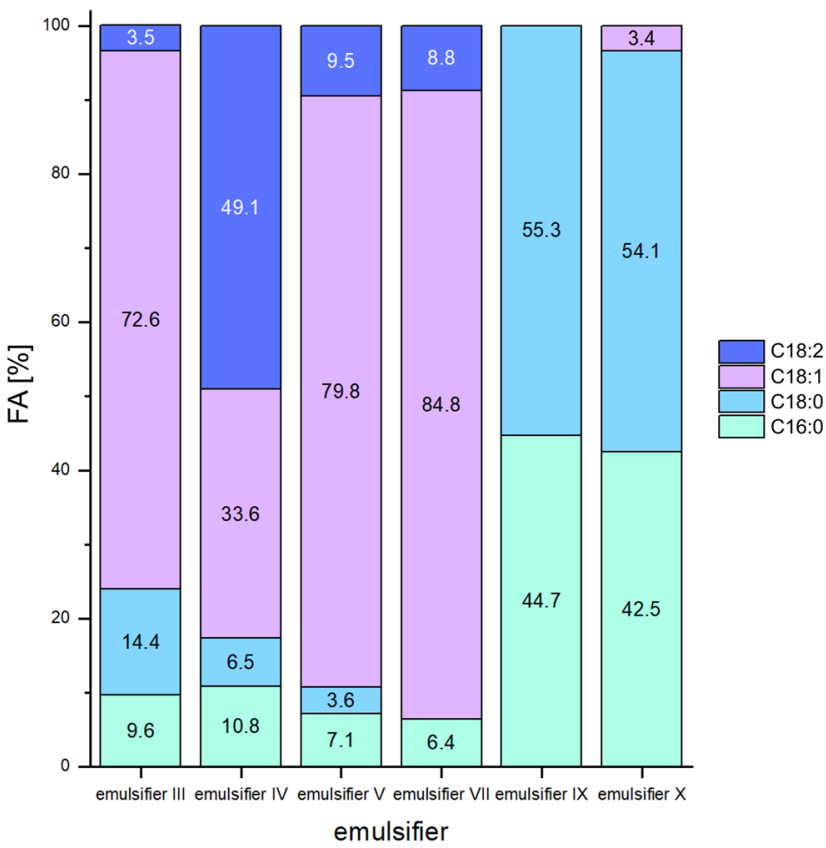

Fig. 3 Percentage fatty acid (FA) compositions determined by HPLC-MS of six emulsifiers (a) (percentages rounded to one decimal digit) and FA compositions of the vegetable oils (untreated) used consideration of the RF (Tables 1 and 2) and correlations (Table S3 in the Online Resource) determined for the corresponding $\mathrm{C} 18: 1$ derivatives. To check how realistic the data obtained was, the FA compositions (Fig. 3a) of three distilled MG and three MG/DG emulsifiers were calculated by summarizing the amounts of the C16:0, C18:0, C18:1, and $\mathrm{C} 18: 2$ representatives (initially determined as $\mathrm{FA}, \mathrm{MG}$, DG, and TG) and calculating their relative contents.

According to the specification sheet, emulsifier III originated from partially hydrogenated rapeseed oil. The presence of lipid classes with unsaturated FA, wherein the C18:2 content was lower than that of unprocessed rapeseed oil ( $4 \%$ compared to $15-30 \%$ [25], Fig. 3), and a higher amount of C18:0 compared to the native oil ( $14 \%$ compared to $\leq 3 \%$ [25], Fig. 3), affirmed its partial hydrogenation. Both emulsifiers IV and V consisted of sunflower oil, whereat for emulsifier IV refined oil and for emulsifier $\mathrm{V}$ high-oleic sunflower oil were specified. Based on the results for the lipid class representatives obtained by HPLC-MS analyses, the calculated FA compositions (Fig. 3a) matched very well the known FA compositions of the native oils used for the emulsifiers' production (Fig. 3b [25]). These findings confirmed the HPLC-MS method including the RF quantitation strategy, and additionally the estimation performed for C18:2 representatives, as a suitable approach. Especially for emulsifier IV, the estimation added clarification to the conspicuousness regarding the absolute amount, since

b

\begin{tabular}{|c|c|c|c|}
\hline \multirow[b]{2}{*}{ FA } & \multicolumn{3}{|c|}{ FA composition of MG emulsifier [\%] } \\
\hline & $\begin{array}{l}\text { emulsifier III } \\
\text { (partially hydrogenated } \\
\text { rapeseed oil) }\end{array}$ & $\begin{array}{l}\text { emulsifier IV } \\
\text { (refined sunflower oil) }\end{array}$ & $\begin{array}{l}\text { emulsifier V } \\
\text { (high-oleic sunflower oil) }\end{array}$ \\
\hline $\begin{array}{l}\text { C16:0 } \\
\text { C18:0 } \\
\text { C18:1 } \\
\text { C18:2 }\end{array}$ & $\begin{array}{l}2.5-7.0 \\
0.8-3.0 \\
51-70 \\
15-30\end{array}$ & $\begin{array}{l}5.0-7.6 \\
2.7-6.5 \\
14-39 \\
48-70\end{array}$ & $\begin{array}{l}2.6-5.0 \\
2.9-6.2 \\
75-91 \\
2.1-17\end{array}$ \\
\hline C18:2 & \multicolumn{3}{|c|}{ FA composition of MG/DG emulsifier [\%] } \\
\hline FA & $\begin{array}{l}\text { emulsifier VII } \\
\text { (not specified) }\end{array}$ & $\begin{array}{l}\text { emulsifier IX } \\
\text { (fully hydrogenated palm } \\
\text { based oil) }\end{array}$ & $\begin{array}{l}\text { emulsifier X } \\
\text { (hydrogenated palm } \\
\text { glycerides) }\end{array}$ \\
\hline C16:0 & 5.7 & $39-48$ & $39-48$ \\
\hline C18:0 & 1.7 & $3.5-6.0$ & $3.5-6.0$ \\
\hline C18:1 & 79 & $34-44$ & $34-44$ \\
\hline C18:2 & 12 & $9.0-12$ & $9.0-12$ \\
\hline $\begin{array}{l}\text { sum } \\
\mathrm{C} 18\end{array}$ & & $47-62$ & $47-62$ \\
\hline
\end{tabular}

for the production of the emulsifiers according to Codex Alimentarius [25] and the specification sheet, respectively (b). Respective raw materials are given in brackets 
consideration of the $\mathrm{C} 12: 0-\mathrm{C} 18: 1$ representatives only delivered merely $50 \%$ of the emulsifier's components (Table 3).

The specification sheet of emulsifier VII did not mention the vegetable oil but data for the FA composition that matched well the composition calculated after determination of the lipid class representatives by HPLC-MS (Fig. 3). For emulsifiers IX and X, produced from fully hydrogenated palm-based oil and hydrogenated palm glycerides, respectively, similar FA compositions were determined by HPLC-MS (Fig. 3a). Generally, the obtained data for the C18:0 and C16:0 contents of emulsifiers IX and X matched very well the data of hydrogenated palm oil (sum of C18 fatty acid moieties and C16:0 [25], Fig. 3), with still a small amount of unsaturated C18:1 found in emulsifier X (Fig. 3a). Moreover, the results obtained by the developed HPLC-MS method were in accordance with the results obtained via GC-FID, shown by comparison with previously published data [4]. Two of the investigated emulsifiers have already been analyzed in the previous study by GC-FID and the results matched very well. For emulsifier $\mathrm{V}$, about $80 \%$ C18:1 and 10\% C18:2 were determined by HPLC-MS (Fig. 3a), which corresponded very well to $80 \% \mathrm{C} 18: 1$ and 10\% C18:2 for a long-chain unsaturated MG emulsifier analyzed by GC-FID in the previous study [4]. Likewise, the FA composition of emulsifier IX that showed about 45\% C16:0 and 55\% C18:0 (Fig. 3a) matched very well the composition of a medium-chain saturated MG/DG emulsifier (43.3\% C16:0 and 54.5\% C18:0) analyzed by GC-FID [4].

To check the assumption of present DG and TG containing different FA, exemplarily the DG containing a C16:0 and a C18:0 FA was considered (see Table S2 for detailed information on $\mathrm{m} / \mathrm{z}$ values in the Online Resource). Amounts were estimated for emulsifiers VIII, IX, and X, after taking the mean RF and correlations for 1,2-DG and 1,3-DG that exclusively contained $\mathrm{C} 16: 0$ or C18:0 into account. Although the consideration of all theoretically possible DG and TG with varying FA was not in the focus of this study, the results for the estimation of the DG with different FA (C16:0 and C18:0) (Table 4) emphasized the great possibilities of HPLC-MS and the comprehensive information provided by this cost-efficient method.

Overall, the determined amounts of MG for all emulsifiers matched well the quantities given in the specification sheets of the manufactures (Tables 3 and 4 and Tables S5-14 in the Online Resource), and in all except one (emulsifier VIII) of the emulsifiers, an amount of MG and $\mathrm{DG} \geq 70 \%$ was determined, as claimed by Commission Regulation (EU) No 231/2012 [1]. Emulsifier VIII showed only $\sim 60 \%$ of $\mathrm{MG}$ and $\mathrm{DG}$, whereas the $\mathrm{MG}$ content of $\sim 30 \%$ fitted the specification. Similarly, MG contents of emulsifiers VII and X matched the specified values, while the DG amounts were determined to $24 \%$ compared to $\sim 30 \%$ stated in the specification. None of the considered TG were found in distilled MG emulsifiers while in one of them (emulsifier III), FA were determined (Table 3). In MG/DG emulsifiers, both TG $(\leq 3 \%)$ and FA were determined (Table 4), with two emulsifiers showing $2 \%$ (emulsifiers IX and X) of FA and one 7\% (emulsifier VIII).

\section{Conclusions}

The developed HPLC-MS method was shown to be well suited for the separation and sensitive determination of 29 considered analytes within 21 peaks from the lipid classes FA, MG, DG, and TG with the fatty acids C12:0-C18:1, when also the separation of positional isomers was enabled. This provided a relatively simple and rather inexpensive approach that offered the comprehensive analysis of E 471 emulsifiers applying a single quadrupole mass spectrometer. Quantitation by the developed RF strategy, while calibrating with only the $\mathrm{C} 16: 0$ representatives, provided reliable results without the need of plenty individual standard substances. The simultaneous analysis of all lipid classes with a commonly applied HPLC-(ESI)MS system offered the determination of the constituents of MG and MG/DG emulsifiers and, thus, represents a meaningful alternative to other methods covering only single lipid classes or to the HPTLC screening method that offers sum values for each lipid class. Moreover, based on the analyzed quantities of the single constituents, an additional statement about the FA composition is possible. Therefore, the analysis of emulsifiers by the developed HPLC-MS method will enable a reliable quality control for manufacturers and give food producers the opportunity to specifically select and dose these food additives according to the required techno-functional properties in foodstuffs.

Supplementary Information The online version contains supplementary material available at https://doi.org/10.1007/s00217-021-03684-3.

Acknowledgements The authors express thanks to Oleochemicals (Hamburg, Germany), DuPont Danisco (Neu-Isenburg, Germany), and BASF (Illertissen, Germany) for providing E 471 emulsifiers.

Author contributions Conceptualization: $\mathrm{CO}$; funding acquisition: $\mathrm{CO}$ and WS; investigations: CO and DS; methodology: CO, DS, and KL; project administration: $\mathrm{CO}, \mathrm{MG}$, and WS; resources: $\mathrm{CO}, \mathrm{MG}$, and WS; supervision: CO, MG, and WS; validation: DS; visualization: DS; writing —original draft: DS; writing—review and editing: CO, DS, $\mathrm{MG}$, and WS.

Funding Open Access funding enabled and organized by Projekt DEAL. This IGF Project of the FEI (Forschungskreis der Ernährungsindustrie e.V., Bonn, Germany) was supported via AiF (Arbeitsgemeinschaft industrieller Forschungsvereinigungen e.V., Cologne, Germany) within the program for promoting the Industrial Collective Research (IGF) of the German Ministry of Economic Affairs 
and Energy (BMWi), based on a resolution of the German Parliament (project AiF $19355 \mathrm{~N}$ ).

\section{Compliance with ethical standards}

Conflict of interest The authors declare that they have no conflict of interest or competing interests.

Compliance with ethics requirements This article does not contain any studies with human or animal subjects.

Financial interest The authors have no relevant financial or non-financial interests to disclose.

Open Access This article is licensed under a Creative Commons Attribution 4.0 International License, which permits use, sharing, adaptation, distribution and reproduction in any medium or format, as long as you give appropriate credit to the original author(s) and the source, provide a link to the Creative Commons licence, and indicate if changes were made. The images or other third party material in this article are included in the article's Creative Commons licence, unless indicated otherwise in a credit line to the material. If material is not included in the article's Creative Commons licence and your intended use is not permitted by statutory regulation or exceeds the permitted use, you will need to obtain permission directly from the copyright holder. To view a copy of this licence, visit http://creativecommons.org/licenses/by/4.0/.

\section{References}

1. The European Parliament and the Council of the European Union (2012) Commission Regulation (EU) No 231/2012 of 9 March 2012 laying down specifications for food additives listed in Annexes II and III to Regulation (EC) No 1333/2008 of the European Parliament and of the Council. Off J L 83:1-295

2. The European Parliament and the Council of the European Union (2008) Regulation (EC) No 1333/2008 of the European Parliament and of the Council of 16 December 2008 on food additives. Off $\mathbf{J}$ L 354:16-33

3. Norn V (2015) Emulsifiers in Food Technology, second edn. Wiley Blackwell, Chichester, New York

4. Blankart M, Kratzner C, Link K et al (2020) Technical emulsifiers in aerosol whipping cream - Compositional variations in the emulsifier affecting emulsion and foam properties. Int Dairy J 102:104578. https://doi.org/10.1016/j.idairyj.2019.104578

5. Lin J-T, Woodruff CL, McKeon TA (1997) Non-aqueous reversedphase high-performance liquid chromatography of synthetic triacylglycerols and diacylglycerols. J Chromatogr A 782:41-48. https://doi.org/10.1016/S0021-9673(97)00482-2

6. Lísa M, Lynen F, Holcapek M et al (2007) Quantitation of triacylglycerols from plant oils using charged aerosol detection with gradient compensation. J Chromatogr A 1176:135-142. https:// doi.org/10.1016/j.chroma.2007.10.075

7. Perona J, Ruizgutierrez V (2003) Simultaneous determination of molecular species of monoacylglycerols, diacylglycerols and triacylglycerols in human very-low-density lipoproteins by reversedphase liquid chromatography. J Chromatogr B 785:89-99. https:// doi.org/10.1016/S1570-0232(02)00861-9

8. Cossignani L, Luneia R, Damiani P et al (2006) Analysis of isomeric diacylglycerolic classes to evaluate the quality of olive oil in relation to storage conditions. Eur Food Res Technol 224:379383. https://doi.org/10.1007/s00217-006-0327-8

9. Holcapek M, Lísa M, Jandera P et al (2005) Quantitation of triacylglycerols in plant oils using HPLC with APCI-MS, evaporative light-scattering, and UV detection. J Sep Sci 28:1315-1333. https ://doi.org/10.1002/jssc.200500088

10. Suman M, Silva G, Catellani D et al (2009) Determination of food emulsifiers in commercial additives and food products by liquid chromatography/atmospheric-pressure chemical ionisation mass spectrometry. J Chromatogr A 1216:3758-3766. https://doi. org/10.1016/j.chroma.2009.02.055

11. Zeb A, Murkovic M (2010) Analysis of triacylglycerols in refined edible oils by isocratic HPLC-ESI-MS. Eur J Lipid Sci Technol 112:844-851. https://doi.org/10.1002/ejlt.201000064

12. Beccaria M, Sullini G, Cacciola F et al (2014) High performance characterization of triacylglycerols in milk and milk-related samples by liquid chromatography and mass spectrometry. J Chromatogr A 1360:172-187. https://doi.org/10.1016/j.chroma.2014.07.073

13. Holčapek M, Cífková E, Červená B et al (2015) Determination of nonpolar and polar lipid classes in human plasma, erythrocytes and plasma lipoprotein fractions using ultrahigh-performance liquid chromatography-mass spectrometry. J Chromatogr A 1377:85-91. https://doi.org/10.1016/j.chroma.2014.12.023

14. Chu B-S, Nagy K (2013) Enrichment and quantification of monoacylglycerols and free fatty acids by solid phase extraction and liquid chromatography-mass spectrometry. J Chromatogr B 932:50-58. https://doi.org/10.1016/j.jchromb.2013.05.026

15. Verleyen T, Verhe R, Garcia L et al (2001) Gas chromatographic characterization of vegetable oil deodorization distillate. J Chromatogr A 921:277-285. https://doi.org/10.1016/S0021 $-9673(01) 00881-0$

16. Satou C, Goto H, Yamazaki Y et al (2017) Modified gas chromatographic method to determine monoacylglycerol and diacylglycerol contents in edible fats and oils. J Oleo Sci 66:601-606. https://doi. org/10.5650/jos.ess 16143

17. American Oil Chemists' Society (2017) AOCS Official Method Cd 11b-91: Mono- and diglycerides by capillary gas chromatography. In: Firestone D (eds) Official Methods and Recommended Practices of the AOCS, seventh ed., Champaign, Illinois

18. Zhu H, Clegg MS, Shoemaker CF et al (2013) Characterization of diacylglycerol isomers in edible oils using gas chromatographyion trap electron ionization mass spectrometry. J Chromatogr A 1304:194-202. https://doi.org/10.1016/j.chroma.2013.06.058

19. Metcalfe LD, Schmitz AA, Pelka JR (1966) Rapid preparation of fatty acid esters from lipids for gas chromatographic analysis. Anal Chem 38:514-515. https://doi.org/10.1021/ac60235a044

20. Bannon CD, Breen GJ, Craske JD et al (1982) Analysis of fatty acid methyl esters with high accuracy and reliability. J Chromatogr A 247:71-89. https://doi.org/10.1016/S0021-9673(00)84857-8

21. La Nasa J, Degano I, Brandolini L et al (2018) A novel HPLCESI-Q-ToF approach for the determination of fatty acids and acylglycerols in food samples. Anal Chim Acta 1013:98-109. https:// doi.org/10.1016/j.aca.2017.12.047

22. Oellig C, Brändle K, Schwack W (2018) Characterization of E 471 food emulsifiers by high-performance thin-layer chromatography-fluorescence detection. J Chromatogr A 1558:69-76. https ://doi.org/10.1016/j.chroma.2018.05.010

23. Deutsches Institut für Normung e.V. (2008) DIN 32645 Chemical analysis - decision limit, detection limit and determination limit under repeatability conditions - terms, methods, evaluation, Beuth Verlag, Berlin, Germany

24. Blankart M, Oellig C, Averweg S et al (2020) Effect of storage at high temperature on chemical (composition) and 
techno-functional characteristics of E471 food emulsifiers applied to aerosol whipping cream. J Food Eng 277:109882. https://doi. org/10.1016/j.jfoodeng.2019.109882

25. Joint FAO/WHO Codex (2001) Alimentarius Commission: The Codex Alimentarius - Fats, Oils and Related Products, second revised ed., Rome, Italy
Publisher's Note Springer Nature remains neutral with regard to jurisdictional claims in published maps and institutional affiliations. 